J. Dairy Sci. 90:1607-1610

doi:10.3168/jds.2007-90-4-1607

(c) American Dairy Science Association, 2007.

\title{
Journal of Dairy Science 2006 Editorial Report
}

\author{
Gary W. Rogers, Editor-in-Chief
}

Department of Animal Science, University of Tennessee, Knoxville 37996

I am pleased to bring you another extremely positive report on the performance of the Journal of Dairy Science (JDS). The Journal of Dairy Science had another very successful year in 2006 and reached several new milestones for performance. The outstanding staff members at ADSA headquarters and the Senior Editors and Section Editors are to be congratulated on a fantastic job in 2006. The staff members that work on JDS are extremely efficient and very professional in their work. I would especially like to acknowledge the efforts of Susan Pollock, the Managing Editor of JDS and FASS Director of Editorial and Production, and Louise Adam, the Technical Editor of JDS and Assistant Director of Editorial and Production. They do an excellent job of keeping me informed of new issues on the publishing front, and they make sure that each edition of JDS is ready in a timely fashion. Jeremy Holzner should also be recognized for his contributions to the publication process as he coordinates the efforts on Manuscript Central. Jeremy has had an especially challenging year as he has successfully helped us migrate to a new version of Manuscript Central. This migration was not easy, but the new version of Manuscript Central is more powerful than the previous version. Sharon Frick (Production Coordinator), Ted Veatch (Figure Processor), and Lisa Krohn, Susan Krusemark, and Mandy Maiden (Technical Editors) help to maintain the high quality of the journal. The FASS staff are extremely efficient and we owe them a huge thank you. The overall leadership of ADSA by Peter Studney has been outstanding as well. Peter recognizes the importance of JDS and understands that JDS is our most valuable asset.

The Journal of Dairy Science continues to be the best scientific journal that serves the international community of dairy scientists. The impact factor for JDS from the most recent Institute for Scientific Information report increased to 2.24 , which is the second highest impact factor in the category of agriculture, dairy, and animal science (which includes 43 major journals). The impact factor is based primarily on journal citation reports. Animal Genetics is the only journal in the category that has a higher impact factor, and their impact factor is 2.437 , which is only slightly higher that the impact factor for JDS. The outstanding impact factor for JDS reflects the dedication and hard work of authors, reviewers, editors, and staff who work on JDS.

In 2006, JDS published a total of 522 articles and 4961 pages (Tables 1 and 2). This would be the fourth consecutive year that JDS has published more than 400 manuscripts and more than 4000 pages. In 2006, JDS published 450 research papers, 40 Our Industry Today (OIT) papers, and 5 Invited Reviews. In April, JDS published a special issue to celebrate the ADSA Centennial. The special issue followed the tradition of the 50th and 75th anniversary issues by publishing 22 invited papers that reviewed advances in dairy science since the 75th anniversary. In addition, JDS published 5 symposium papers in the online-only supplement.

The largest section in JDS in 2006 was Physiology and Management with 144 research papers (Table 3). The second largest section was the Nutrition, Feeding, and Calves with 125 research papers. The Dairy Foods section and the Genetics and Breeding section published 107 and 74 research papers, respectively. The Physiology and Management section also published 20 OIT papers, and the Nutrition, Feeding, and Calves section published 7 OIT papers. Of the article types other than full-length research papers or OIT papers, Short Communications were most frequent. In 2006, JDS published 32 Short Communications, 5 Invited Reviews, 12 Technical Notes, and 2 Letters to the Editor.

The total time from receipt of a manuscript until final publication in JDS continues to be outstanding (Table 1). In 2006, the average time in review for accepted papers was 125 days, and the average time from acceptance until the papers were ready for posting and printing was 116 days. It takes about 10 days to get the posting completed so total average production time after acceptance was 126 days. The average time from submission to publication for an accepted paper was 251 days in 2006. Factors increasing the overall publication time in 2006 compared with 2005 included the publication of the special centennial issue in April (articles that would have been published in a regular April issue were pushed back a month, with some 
Table 1. Journal of Dairy Science statistics for 2006 compared with previous years

\begin{tabular}{lrrrrrrrr}
\hline & 2006 & 2005 & 2004 & 2003 & 2002 & 2001 & 2000 & 1999 \\
\hline Avg. papers received/mo & 74 & 76 & 65 & 56 & 53 & 50 & 44 & 42 \\
Avg. papers accepted/mo & 46 & 42 & 39 & 38 & 37 & 31 & 30 & 28 \\
Avg. papers published/mo & 45 & 40 & 40 & 38 & 33 & 30 & 29 & 28 \\
Pages published & 4,961 & 4,451 & 4,562 & 4,341 & 3,633 & 3,091 & 3,413 & 2,944 \\
Average review time (d) & 125 & 122 & 132 & 105 & 121 & 158 & 158 & 180 \\
Average production time (d) & 126 & 92 & 135 & 151 & 159 & 125 & 137 & 115 \\
Average total time (d) & 251 & 214 & 267 & 256 & 280 & 283 & 295 & 295 \\
\hline
\end{tabular}

carry-over for 2 or 3 months). The FASS editorial office also hired 2 new technical editors in 2006; both are now fully trained, and we anticipate that the production times will fall in 2007.

Another important statistic for JDS is the time that it takes to get the first decision on a paper. The average time from submission to the first decision is now below 39 days; this reflects good work on the part of most reviewers. The average time from submission to reviewer assignment is less than 3 days. Many papers have an initial decision within 3 weeks after submission, and some of the very best papers are accepted within 3 weeks after submission. Other papers that require multiple revisions can still take several months before a final decision is made. Overall, the Senior Editors, Section Editors, and reviewers have done an outstanding job in 2006.

The rate of new submissions to JDS continues to be outstanding. In 2006, JDS had 904 new articles submitted for consideration. In addition, JDS had 916 revised papers submitted in 2006 . The total number of manuscripts handled by our Senior Editors and Section Editors in 2006 was 1820! This is a large number of papers to handle in one year, and it bodes well for a strong JDS in the near future. Approximately $30 \%$ of the new papers submitted to JDS were from US authors with another $9 \%$ of papers from Canadian authors, resulting in the combined percentage of new articles submitted for publication in JDS from North American authors at less than $40 \%$. Just over $60 \%$ of new articles were from authors outside North America. Approximately 55 to $60 \%$ of the papers submitted to JDS are eventually accepted so we expect another strong year of publishing in 2007.

\section{JDS Faces Possibility of Open Access}

A current issue that is important for the future of JDS is the concept of open access (OA). Open access is a movement to require that government-funded (and some privately funded) research be available to the public as soon as published. The Journal of Dairy Science now has articles available to the public 1 year after publication, but OA could require that publications be available to the public immediately upon publication. If or when OA becomes fully required, it will

Table 2. Journal of Dairy Science manuscript and page statistics by article type for 2006

\begin{tabular}{|c|c|c|c|c|c|c|c|c|}
\hline \multirow[b]{2}{*}{ Month } & \multicolumn{2}{|c|}{ Research } & \multicolumn{2}{|c|}{$\begin{array}{c}\text { Our Industry } \\
\text { Today }\end{array}$} & \multicolumn{2}{|c|}{ Invited Review } & \multicolumn{2}{|c|}{ Symposium } \\
\hline & Papers & Pages & Papers & Pages & Papers & Pages & Papers & Pages \\
\hline January & 34 & 322 & 4 & 34 & 1 & 14 & 0 & 0 \\
\hline February & 38 & 397 & 1 & 11 & 1 & 19 & 0 & 0 \\
\hline March & 35 & 301 & 2 & 8 & 0 & 0 & 0 & 0 \\
\hline April & 0 & 0 & 0 & 0 & $22 *$ & 247 & 0 & 0 \\
\hline May & 45 & 438 & 4 & 41 & 1 & 12 & 0 & 0 \\
\hline June & 40 & 362 & 8 & 85 & 2 & 29 & 0 & 0 \\
\hline July & 46 & 406 & 5 & 50 & 0 & 0 & 0 & 0 \\
\hline August & 42 & 404 & 5 & 46 & 0 & 0 & 0 & 0 \\
\hline September & 45 & 413 & 5 & 39 & 0 & 0 & 0 & 0 \\
\hline October & 39 & 354 & 1 & 11 & 0 & 0 & 0 & 0 \\
\hline November & 39 & 360 & 2 & 17 & 0 & 0 & 0 & 0 \\
\hline December & 47 & 449 & 3 & 28 & 0 & 0 & 0 & 0 \\
\hline E-Supplement & 0 & 0 & 0 & 0 & 0 & 0 & 5 & 64 \\
\hline Total & 450 & 4,206 & 40 & 370 & 27 & 321 & 5 & 64 \\
\hline
\end{tabular}

*Special review issue to celebrate ADSA Centennial. 
Table 3. Journal of Dairy Science research manuscripts and page statistics by science section ${ }^{1}$ for 2006

\begin{tabular}{|c|c|c|c|c|c|c|c|c|}
\hline \multirow[b]{2}{*}{ Month } & \multicolumn{2}{|c|}{ DF } & \multicolumn{2}{|c|}{$\mathrm{PM}$} & \multicolumn{2}{|c|}{ NFC } & \multicolumn{2}{|c|}{ GB } \\
\hline & Papers & Pages & Papers & Pages & Papers & Pages & Papers & Pages \\
\hline January & 9 & 96 & 7 & 59 & 14 & 137 & 4 & 30 \\
\hline February & 12 & 135 & 12 & 103 & 10 & 132 & 4 & 27 \\
\hline March & 17 & 151 & 8 & 65 & 10 & 85 & 0 & 0 \\
\hline April & 0 & 0 & 0 & 0 & 0 & 0 & 0 & 0 \\
\hline May & 8 & 83 & 8 & 79 & 17 & 167 & 12 & 109 \\
\hline June & 7 & 75 & 16 & 129 & 9 & 90 & 8 & 68 \\
\hline July & 13 & 110 & 18 & 143 & 9 & 108 & 6 & 45 \\
\hline August & 10 & 111 & 17 & 147 & 6 & 68 & 9 & 78 \\
\hline September & 9 & 83 & 12 & 111 & 15 & 138 & 9 & 81 \\
\hline October & 8 & 81 & 13 & 114 & 12 & 118 & 6 & 41 \\
\hline November & 6 & 67 & 14 & 126 & 13 & 125 & 6 & 42 \\
\hline December & 8 & 76 & 19 & 185 & 10 & 110 & 10 & 78 \\
\hline Total & 107 & 1,068 & 144 & 1,261 & 125 & 1,278 & 74 & 599 \\
\hline
\end{tabular}

${ }^{1} \mathrm{DF}=$ Dairy Foods; PM = Physiology and Management; NFC = Nutrition, Feeding, and Calves; and GB $=$ Genetics and Breeding. Table does not include Our Industry Today manuscripts, invited reviews, or symposium papers.

considerably change the publishing approach used by many journals. It will affect JDS as well, but it is difficult to predict how JDS will change in response to $\mathrm{OA}$ requirements when the requirements and policies are finalized. Almost certainly, journals like JDS will rely more on funding from authors. Increasing traditional membership dues to support publication efforts is another option, but this could reduce the number of members in ADSA.

Librarians at universities began a push for OA in response to escalating journal prices and stagnant or decreasing serials budgets. Over time, researchers, universities, US government funding agencies (e.g., $\mathrm{NIH}$ ), Congress (the Cornyn-Lieberman bill to require OA for all government-funded research), and European funding and government agencies (e.g., Wellcome Trust, INRA) have begun to weigh in on the side of OA as well. Many of these groups would like unrestricted access and use of electronic serials without readers or end users paying for access.

What Will JDS Do About Open Access? Journal of Dairy Science will need to replace subscription revenue with other revenue streams to remain financially viable. Some of the revenue streams that various journals are considering include the following: author pays for full cost of publication (author pays model), creating journal sponsorships, increased advertising, and earmarking a portion of membership dues to a journal (which doesn't create a new revenue stream). The Board of Directors for ADSA and JDS are not sure of the exact approach that will be taken for replacing subscription revenue when (and if) OA becomes a requirement, but most likely more of the cost of publishing will be borne by authors. This is the model chosen by numerous other scientific publishers where author page charges will be dramatically increased if OA becomes mandatory. The new fees for publishing a paper will range between $\$ 2,500$ and $\$ 3,500$ per article for most of these journals that have already decided how they will offset the lack of subscription revenue.

\section{Changes in Editors and Editorial Board}

Retiring Senior Editors from 2006 include Jeff Stevenson (Physiology and Management) and Wayne Kel$\operatorname{logg}$ (Nutrition, Feeding, and Calves). The current editors would like to give a special thanks to the 2 retiring editors. Lorraine Sordillo and Dave Schingoethe have replaced Jeff and Wayne as Senior Editors in their respective sections. New Section Editors for JDS include Matt Lucy (Physiology and Management) and Keith Cummins (Nutrition, Feeding, and Calves). These 2 new Section Editors began their duties in the fall of 2006.

The JDS would like to thank the Editorial Board and the very large number of ad hoc reviewers for their service to JDS this past year. The timely and dedicated effort provided by the Editorial Board and the ad hoc reviewers is essential to maintaining the reputation of JDS, and the efforts of these reviewers are greatly appreciated. Members that retired from the Editorial Board at the end of 2006 include W. R. Butler, D. P. Casper, K. A. Cummins (now Section Editor), G. E. Dahl, F. Elvinger, N. Y. Farkye, B. Geller, M. A. Godkin, E. Hovingh, B. Jayarao, A. Kilara, A. J. McAllister, I. Misztal, and S. Moineau. Newly appointed Editorial Board members include S. Brotherstone, R. Chebel, A. Ealy, V. Fellner, E. Hynes, D. Jones, H. Khatib, S. McDougall, J. McNamara, L. Metzger, M. Nunez, S. Rankin, and J. Vicini. The Journal of Dairy 
Science continues to see increased contributions from scientists outside of the US, and the new Editorial Board is designed to reflect the importance of international participation.

The current Journal Management Committee is chaired by Rafael Jimenez-Flores. Other members of the current Journal Management Committee are John Lucey, John Bernard, and Jesse Goff. Please feel free to communicate with a member of Journal Management Committee, one of the Editors or the Editor-inChief if you have comments or suggestions related to JDS. 